NASA Technical Memorandum 85798

\title{
THREE-DIMENSIONAL FINITE-ELEMENT ANALYSIS OF CHEVRON-NOTCHED FRACTURE SPECIMENS
}

I, S. RAJU AND J. C. NEWMAN, JR,

JULY 1984

\section{N/SA \\ National Aeronautics and \\ Space Administration


THREE-DIMENSIONAL FINITE-ELEMENT ANALYSIS OF

CHEVRON-NOTCHED FRACTURE SPECIMENS

\section{S. Raju ${ }^{1}$ and J. C. Newman, Jr. ${ }^{2}$ NASA Langley Research Center Hampton, Virginia 23665}

\section{SUMMARY}

In this paper, stress-intensity factors and load-1ine displacements have been calculated for chevron-notched bar and rod fracture specimens using a three-dimensional finite-element analysis. Both specimens were subjected to simulated wedge loading (elther uniform applied displacement or uniform applied load). The chevron-notch sides and crack front were assumed to be straight. Crack-1ength-to-specimen width ratios $(a / w)$ ranged from 0.4 to 0.7. The width-to-thickness ratlo $(w / B)$ was 1.45 or 2 . The bar specimens had a helght-to-width ratio of 0.435 or 0.5 . Finite-element models were composed of singularity elements around the crack front and 8-noded isoparametric elements elsewhere. The models had about 11,000 degrees of freedom. Stressintensity factors were calculated by using a nodal-force method for distribution along the crack front and by using a compliance method for average values. The stress-intensity factors and load-1ine displacements are presented and compared with experimental solutions. from the literature. The stress-intensity factors and load-1ine displacements were about 2.5 and 5 percent lower than the reported experimental values, respectively.

${ }^{1}$ Senior Sclentist, Vigyan Research Assoclates, Hampton, VA 23666. Work 2 performed under NASA contract NAS1-17090.

2 Senior Scientist, NASA Langley Research Center, Hampton, VA 23665. 


\section{INTRODUCTION}

The chevron-notched specimens $[1,2]$, shown in F1gure 1, are smal1 fracture toughness specimens being consldered for use in standard tests by the American Soclety for Testing and Materlals (ASTM) Committee E24. Because they are smal1 ( 5 to $25 \mathrm{~mm}$ thick) and because they require no fatigue precracking, they are well suited for quality control and materlals toughness evaluation specimens. Currently, these specimens can only be used for high-strength alloys, ceramics, and other such low toughness brittle materials. Further advances in elastic-plastic fracture mechanics are needed to use these specimens for ductile materials.

The unique features of a chevron-notched specimen, over conventional fracture-toughness specimens, are: (1) the extremely high stress concentration at the tip of the chevron-notch, and (2) the development of a minimum stress-intensity factor as the crack grows. The high stress concentration at the tip of the chevron-notch causes a crack to initiate at a low applied load, eliminating the need to precrack a specimen, a costly and time consuming procedure. The minimum stress-intensity factor allows the fracture toughness to be evaluated from this fallure (maximum) load without the need to make a load-displacement record, such as currently used in the ASTM E399 plane-strain fracture toughness $\left(K_{I c}\right)$ test procedure.

Experimental compliance callbrations of the chevron-notched bar (short bar) and rod (short rod) specimens have been done by Barker and Guest [3], Munz et al. [4], Bubsey et al. [5], Shannon et al. [6], and Barker [7] for the determination of stress-intensity factors. In addition to the experimental callbrations, several analytical attempts have been made. Munz et al. [4] used a quasi-analytical procedure (slice model) developed by Bluhm [8] to analyze the chevron-notched bar specimen. Again, they determined stress- 
intensity factors from the compliance method. But, the experimental and analytical compliance methods give only an "average" stress-intensity factor along the crack front for each crack configuration considered. More rigorous three-dimensional analyses are required to determine stress-intensity factor variation along the crack front. Beech and Ingraffea [9] used a threedimensional finite element method to determine stress-intensity factor distributions along the crack front and stress-intensity factors from analytical compliance for the chevron-notched $\operatorname{rod}(w / B=1.5)$. Their crack front evaluations of stress-intensity factors, however, were in considerable disagreement ( 6 to 17 percent) with their values determined from compliance. But their analytical compliance values were in good agreement with experimental compliance results.

In this paper, stress-intensity factors and load-1ine displacements have been calculated by a three-dimensional finite-element analysis [10] for chevron-notched bar (square and rectangular) and rod fracture specimens. The specimens were subjected to simulated wedge loading (either uniform applied displacement or uniform applied load). The chevron-notch sides and crack front were assumed to be straight. Crack-length-to-specimen width ratios $(a / w)$ ranged from 0.4 to 0.7 . The width-to-thickness ratio (w/B) was 1.45 or 2. The bar specimens had a height-to-width ratio (H/B) of 0.435 or 0.5 . Stress-intensity factors were calculated by using a nodal-force method [10] for distributions along the crack front and by using a compliance method for average values. The minimum stress-intensity factors for five particular configurations were evaluated. Stress-intensity factors and load-1ine displacements are presented and compared with experimental solutions from the 1iterature. 
NOMENCLATURE

a

o

b

B

$\mathbf{E}$

$\mathbf{E}^{*}$

$\mathbf{F}$

$F_{c}$

$\mathbf{F}_{\text {m }}$

$\mathbf{H}$

$\mathbf{K}_{\mathbf{I}}$

$\mathbf{P}$

$\mathrm{V}_{\mathrm{L}}$ displacement at load point

$V_{T}$ displacement at top of specimen along load IIne

w specimen width

$x, y, z \quad$ Cartesian coordinates

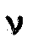

crack length measured from load line

initial crack length (to tip of chevron notch)

length of crack front

specimen thickness (diameter of rod specimen)

Young 's modulus of elasticity

equals $E$ for plane stress and $E /\left(1-v^{2}\right)$ for plane strain

boundary-correction factor determined from compliance method

minimum boundary-correction factor from compliance method

half of specimen helght (radius of rod specimen)

stress-intensity factor (mode I)

applied load

Poisson's ratio

boundary-correction factor determined from nodal-force method

ANALYSIS

Stress-intensity factors and load-1ine displacement for the chevronnotched bar and rod specimens, shown in Figure 1, were obtained by using a three-dimensional finite-element analysis [10]. In this analysis, Poisson's ratio was assumed to be 0.3 . The coordinate systcm used to define the chevron-notched specimens is shown in Figure 2. The specimens are loaded by a knife-edge loading fixture [4] that results in an applied load, $P$, at point L, as shown in Figure 2(a). Specimens may have either a square notch [4] at the load line or a V-notch [7] at the load line (not shown). Only the square 
notch detail was considered herein. The slot helght $(0.03 \mathrm{~B})$ is for a saw blade to cut the chevron-shaped notch. In the present model, the slot height was assumed to be zero. The chevron was modeled and was assumed to have straight sides. Initial crack length, $a_{0}$, is the distance from the load line to the chevron tip (see Fig. 2(b)). The crack length, a, and specimen width, w, are measured from the load 1ine. The crack front (b) was assumed to be straight. Crack-length-to-specimen width ratios (a/w) ranged from 0.4 to 0.7 . The following table gives the specimen dimensions of configurations analyzed herein:

\begin{tabular}{llll}
\hline Specimen & $w / B$ & $\mathrm{a}_{\mathrm{o}} / \mathrm{w}$ & $\mathrm{H} / \mathrm{B}$ \\
\hline Bar & 1.45 & 0.332 & 0.435 \\
Bar & 1.45 & 0.332 & 0.5 \\
Rod & 2 & 0.2 & 0.5 \\
Rod & 1.45 & 0.332 & 0.5 \\
Rod & 2 & 0.2 & 0.5 \\
\hline
\end{tabular}

The configurations with $\mathrm{H} / \mathrm{B}=0.5$ have been selected for possible standarization by ASTM Committee E24.

\section{Finite-Element Idealization}

Two types of elements (isoparametric and singular [10]) were used in combination to model the specimens. Figure $3(a)$ shows a typical finiteelement model for the chevron-notched bar. The model idealized one-quarter of the specimen and employed about 11,000 degrees of freedom (2,960 elements). The isoparametric elght-noded hexahedron elements were used everywhere except at the crack front, where elght singularity elements shaped like pentahedrons were used. The singularity elements produced a square-root singularity in 
stress and strain at the crack front. A typlcal finite-element pattern on the crack plane is shown in Figure $3(\mathrm{~b})$. Thls vlew shows the crack plane for an a/w ratio of 0.55 . One-half of the specimen thickness (B) was modeled with 10 layers. Figures $3(c)$ and $3(d)$ show an end view of the bar and rod specimen, respectively. The notch height was at $0.35 \mathrm{H}$.

To evaluate the finite-element mesh pattern used around the crack front in the three-dimensional models, two- and three-dimensional finite-element analyses of through-the-thickness edge cracks subjected to wedge loading were also analyzed. The two-dimensional analysis used a mesh pattern identical to the front view ( $z=0$ plane) shown in Figure $3(a)$. The three-dimensional analysis used the same model as that used for the chevron-notched specimens except that the singularity elements extended all the way across the specimen thickness.

\section{Boundary Conditions and Applied Loading}

Symmetry boundary conditions were applied on the $z=0$ plane (see Fig. 3). On the $y=0$ plane, all nodes were free except those that lie in the shaded region. Here, symmetry boundary conditions were applied. (The intent of the fixed-node condition on the $y=0$ plane was to prescribe zero $v$-displacements for the shaded area. Because of the rectangular mesh Idealization in the $y=0$ plane, however, the $v=0$ condition was only approximately achleved at locations along the edge of the shaded area. This is approximate because the chevron edge (edge of the shaded area) crossed elements that had one or more free nodes.) The specimens were subjected to wedge loading at point $L$ in Figure 2(a). The loading was elther a uniform applied load or a uniform applied displacement across the thickness. 


\section{Stres8-Intensity Factors}

Two methods were used to obtain stress-intensity factors. In the first method, the stress-intensity factor distributions along the crack front from the finite-element models were obtained by using a nodal-force method, detalls of which are given in references 10 and 11 . In this method, the nodal forces normal to the crack plane and ahead of the crack front are used to evaluate the stress-intensity factors.

The mode $I$ stress-intensity factor, $K_{I}$, at any point along the crack front was taken to be

$$
K_{I}=\frac{P}{B \sqrt{w}} F\left(\frac{a}{w}, \frac{z}{b}\right)
$$

where $F$ was determined from the noda1-force method.

In the second method, an "average" stress-intensity factor along the crack front was obtained from specimen compliance as

$$
\mathrm{K}_{I}=\left(\frac{\mathrm{E}^{\prime}}{\mathrm{b}} \frac{\mathrm{dU}}{\mathrm{da}}\right)^{1 / 2}
$$

for the applied load case where $E^{\prime}=E$ for plane stress or $E^{\prime}=E /\left(1-v^{2}\right)$ for plane strain. The total strain energy of the specimen, $U$, was calculated by

$$
U=4 \sum_{i=1}^{n} P_{1} v_{1} / 2
$$

where $P_{1}$ and $V_{1}$ are the load and displacement, respectively, for the $n$ nodes along the load line in the finite-element models. The stressintensity factor from compliance was written as

$$
K_{I}=\frac{P}{B \sqrt{w}} F_{C}\left(\frac{a}{w}\right)
$$

and, therefore, equating equations (2) and (4) gives

$$
F_{c}=\frac{B \sqrt{W}}{P}\left(\frac{E^{\prime}}{b} \frac{d U}{d a}\right)^{1 / 2}
$$


The dU/da in equation (5) was determined from the values of $U$ evaluated at different crack lengths, a. Consider three crack lengths $\left(a_{i}<a_{j}<a_{k}\right)$ and their corresponding total strain energies, $U_{i}, U_{j}$, and $U_{k^{*}}$ The strain energy was fitted to a second degree polynomial in terms of crack length as

$$
\mathrm{U}=\beta_{1}+\beta_{2} a+\beta_{3} a^{2}
$$

The dU/da at crack length $a_{f}$ was determined by

$$
\left.\frac{d U}{d a}\right|_{a_{j}}=\beta_{2}+2 \beta_{3} a_{\jmath}
$$

This slope was used in equation (5) to evaluate the stress-intensity boundarycorrection factor at crack length $\mathbf{a}_{\mathfrak{j}}$.

\section{RESULTS AND DISCUSSION}

In this section, two- and three-dimensional analyses are used to evaluate the accuracy of the finite-element model presented earlier (see Fig. 3). Next, a convergence study is presented for the chevron-notch configuration. Then, the stress-intensity factor variations along the crack front and the stress-intensity factors determined from the analytical compliance method (eq. (5)) are presented for various chevron-notch configurations. Finally, the stress-intensity factors and load-1ine displacements from the present analyses are compared with experimental solutions from the literature. No comparisons are made with Beech and Ingraffea [9] finite-element analysis because different $\mathrm{w} / \mathrm{B}$ ratios were considered.

Two- and Three-Dimensional Through-the-Thickness Crack Configurations

The finite-element Idealization shown in Figure 3 was evaluated by analyzing two- and three-dimensional through-the-thickness crack configurations. 
These evaluations consisted of studying convergence of stress-intensity factors and load-Iine displacements with mesh refinement in the $z=0$ plane and in the thickness direction. A two-dimensional edge-crack configuration, like a double-cantilever beam specimen, was used to arrive at an adequate mesh refinement in the $z=0$ plane and a three-dimensional through-the-thickness crack configuration was used to determine the mesh refinement in the thickness direction.

Two-dimensional configuration.- The finite-element mesh pattern on the $z=0$ plane In FIgure $3(a)$ was used to model a wedge-loaded edge-cracked plate under plane-strain conditions. The results from this analysis are compared with the results from a boundary-collocation analysis [12] in Figure 4. The boundary-collocation analysis was conducted on an edge-cracked plate with the same dimensions as those used in the finite-element analysis except that the square-notch detall at the load point was not modeled. The model used in the collocation analysis was subfected to a line load acting over a small segment of the crack surface at $x=0$. The solid curves in Figures $4(a)$ and $4(b)$ show the boundary-correction factor and the normalized load-point displacement, respectively, from the collocation analysis as a function of a/w. The symbols in Figure $4(\mathrm{a})$ show stress-intensity factors calculated from the finite-element analysis using the nodal-force and compliance methods. The correction factors evaluated from the nodal-force method were about 2 percent lower than those calculated from the collocation analysis, whereas those obtained from the compliance method were about 1.5 percent lower. The normalized load-point displacements obtained from the finite-element analysis (symbols in Fig. $4(\mathrm{~b})$ ) were about 4 percent lower than those calculated from the collocation analysis. Because the results from finite-element and boundary-collocation analyses agreed we11, the mesh pattern 
along the $z=0$ plane in Figure $3(a)$ was considered sufficient for use in the three-dimensional models.

Three-dimensional configurations.- To evaluate the three-dimensional models, a through-the-thickness crack in a square bar configuration was analyzed with 2-, 4-, and 8-equal layers through one-half of the thickness. Stress-intensity boundary-correction factors, determined from the nodal-force method, are shown in Figure 5. The results in the interior of the specimen $(2 z / B<0.75)$ agreed within a few percent for all three models. The correction factors decreased from the middle of the specimen $(2 \mathrm{z} / \mathrm{B}=0)$ to its lowest value at the intersection of the crack with the free surface. The value at the free surface, however, varied with the number of layers (or layer thickness). Hartranft and Sih [13] have shown that the crack-front singularity differs from the square-root singularity in a very thin "boundary layer" near the free surface and that the stress-intensity factors drop off rapidly and equal zero at the surface. Thus, the finite-element method employed here cannot adequately evaluate the stress-intensity factors in this "boundary layer." But the "average" stress-intensity correction factors across the thickness for all three models were in good agreement ( 2 percent) with the plane-strain solution [12].

\section{Chevron-Notch Configurations}

Convergence.- The convergence study in Figure 5 showed that a four-layer model is adequate and yields accurate stress-intensity factors along most of the crack front for through-the-thickness crack configurations. However, for more complex configurations, such as a chevron-notch specimen, the number of layers needed along the crack front may be greater than four. Therefore, two models were considered for a chevron-notched bar configuration $(w / B=2$, $a / w=0.55)$. The first model had 10 layers across half the specimen thickness 
with 5 unequal thickness layers along the crack front. This model is shown in Pigure 3. The second model had 18 layers, with 8 unequal thickness layers along the crack front. A comparison between the stress-intensity factor distributions along the crack front for the 10- and 18-layer models is shown in Figure 6. The center of the specimen is at $2 z / b=0$. The stress-intensity factors for the two models are nearly constant for $2 z / b<0.5$ but increase rapidly as the $2 z / b$ approaches unity (edge of chevron). Results from the two models agreed well for $2 z / b<0.9$. At the chevron-notch location, however, the results were sensitive to layer thickness. Again, as observed in the preceding section on the "boundary layer" effect, the finite-element analysis cannot adequately evaluate the stress-intensity factors at locations where the crack front intersects another boundary. But these results do show that the 10-layer model is sufficient to model the chevron-notched configurations.

Loading conditions.- Because the chevron-notched specimens are loaded with either a knife-edged fixture [4] or a pressurized flat jack [14], two types of loading conditions were applied to some of the bar and rod configurations $(w / B=2, a / w=0.5$ and 0.55$)$. The loadings were either $a$ uniform applied load or a unform applied displacement along the load line. The displacement varlations along the load line for the applied load cases were very small (less than 0.6 percent from the average). For the same total applied load, the displacement variations along the load line for the applied load case were within 0.6 percent of the displacement from the applied displacement case. Likewise, for the same total applied load, the stressintensity factors for the two types of applied loading were in excellent agreement ( 0.1 percent). Thus, the type of applied loading has no significant 
effect on the results. Consequently, all crack configurations considered herein were subjected to a uniform applied loading.

Bar and rod configurations.- The stress-intensity correction factor distributions along the crack front for the square bar and rod conflgurations are given in Tables 1 and 2 for various $a / w$ ratios. Some typical results for the bar configuration $(w / B=2 ; H / B=0.5)$ are shown in Figure 7 for various $a / w$ ratios. Results for $a / w=0.55$ are not shown for clarity. The distributions as a function of $2 z / b$ are similar for all a/w ratios with the lowest values occurring at the center of the specimen $(2 z / b=0)$ and the highest values at the intersection of the crack with the chevron notch $(2 z / b=1)$. These values were about 40 percent higher than the values at the center of the specimens.

Because of the rising stress-intensity factor distribution from the center of specimen to the edge of the chevron-notch, the crack should grow more at the edges of the chevron-notch than at the center of the spectmen, thus causing a reverse-thumbnailing effect. Experimental results from reference 7 confirm this observation.

A comparison between the stress-intensity factor distributions obtained from the three-dimensional finite-element method and from the compliance method is shown in Figure 8. These results are for the square bar configuration $(w / B=2)$ with $a / w=0.5$. This configuration gave the lowest stress-intensity factors for all of the $a / w$ ratios considered. The solid symbols show the distribution as a function of $2 \mathrm{z} / \mathrm{b}$. The dashed-dot and dash-double-dot lines show values determined for the compliance method (eq. (5)) assuming efther plane-stress or plane-strain conditions, respectively. The plane-strain value was about 5 percent higher than the plane-stress value. An experimentally determined compliance value [6] 
assuming plane-stress conditions is shown as the dashed 1ine. The experimental value is about midway between the numerical values for plane stress and plane strain. But based on the previous two-dimensional results, the numerical values from compliance are estimated to be about 1.5 percent lower than the "true" values. Thus, the experimental value and the "corrected" numerical plane-stress value $\left(1.015 \mathrm{~F}_{\mathrm{c}}\right.$ ) would be in very good agreement (about 1 percent). However, the use of the compliance method is, in itself, an approximation. The state-of-stress throughout the specimen is not elther purely plane stress or purely plane strain. But the induced error is probably less than 2 percent.

Stress-intensity correction factors $\left(F_{c}\right)$ determined from compliance (plane stress) for the five configurations considered are shown in Figure 9 for various a/w ratios. For each configuration, these results were fitted to a third degree polynomial equation in terms of $a / w$ to find the minimum value of the correction factor, $F_{m}$. The minimum values are shown as solid symbols. The following table compares these minimum values and those obtained experimentally in reference 6 .

\begin{tabular}{clccccc}
\hline Specimen & $w / B$ & $(a / w)_{m}$ & $F_{m}$ & $1.015 F_{m}$ & $Y_{m}(a)$ & $\begin{array}{c}\text { Percent } \\
\text { difference }\end{array}$ \\
\hline Bar & 1.45 & 0.55 & 27.36 & 27.77 & - & - \\
Barc $^{b}$ & 1.45 & 0.54 & 24.43 & 24.80 & 24.85 & -0.2 \\
Barc & 2 & 0.52 & 29.13 & 29.57 & 29.91 & -1.1 \\
Rod & 1.45 & 0.55 & 28.43 & 28.86 & 29.11 & -0.9 \\
Rod & 2 & 0.52 & 35.40 & 35.93 & 36.36 & -1.2 \\
\hline
\end{tabular}

(a) Reference 6 uses $Y_{\mathrm{m}}$ to denote correction factor.

(b) $\mathrm{H} / \mathrm{B}=0.435$.

(c) $\mathrm{H} / \mathrm{B}=0.5$. 
The $(a / w)_{m}$ value is the crack-length-to-width ratio where the minimum $F$ value, $F_{m}$, occurred in the compliance analysis. The $F_{m}$ values determined from the finite-element analysis are estimated to be about 1.5 percent lower than the "true" solution because the potential energy method gives a lower bound solution and because of comparisons made between fintte-element and boundary-collocation analyses (see Fig. 4(a)). Thus, the "corrected" numerical results for both the square bar and rod specimens are about 1 percent lower than the experimental values [6].

Barker [2] selected the rectangular bar specimen $(\mathrm{H} / \mathrm{B}=0.435)$ to have the same compliance derivative as the $\operatorname{rod}$ specimen $(w / B=1.45)$ and, consequently, the same boundary-correction factor; that is, $F_{m}$ was equal to 26.3 for both specimens. The present finite-element results gave a value of $F_{m}$ as 27.77. This value was close to the finite-element results obtained on the rod specimen with $w / B=1.45$ but was about 4 percent higher than Barker's value. Based on the current analysis, the recommended minimum value is 27.8 for the rectangular bar specimen with $\mathrm{H} / \mathrm{B}=0.435$.

Table 3 gives the normalized displacements, EBV/P, at the midplane $(z=0)$ of the specimen for the load point $(L)$ and for the top of specimen (T) as a function of $a / w$ (see Fig. 2(a)). Some typical numerical results at the top of specimen are compared with experimental results in Figure 10 for the rod specimen with $w / B=2$. The circular and square symbols show experimental [5] and numerical results, respectively. These results are consistent with the comparisons made on two-dimensional analyses in Figure $4(b)$, in that the finite-element results were about 4 to 6 percent lower than the experimental results. Based on beam theory [15], however, about 2 percent of this difference is caused by neglecting the slot height $(0.03 \mathrm{~B})$ made by a saw blade or chevron cutter (see FIg. 2(a)). 
Effect of Polsson's rat10.- Most experimental compliance results reported In the 11terature and the analyses reported herein were made with a Polsson's rat lo of 0.3 . However, Barker [7] used fused quartz which has a Poisson's ratio of 0.17 . Therefore, to evaluate the effect of Poisson's ratio on stress-intensity factors a very limited study was made using the rod configuration with $w / B=1.45$ and $a / w=0.55$. Four different Poisson's ratios, $0.0,0.17,0.3$, and 0.49 , were used in the three-dimensional analyses. The following table shows the normalized stress-intensity factor at midplane $(z=0)$, the average normalized stress-intensity factor, and the load-1ine displacements for various Poisson's ratios.

\begin{tabular}{ccccc}
\hline $\begin{array}{c}\text { Polsson's ratio } \\
\nu\end{array}$ & $\left.\frac{\mathrm{KBw}^{1 / 2}}{\mathrm{P}}\right|_{\mathrm{z}=0}$ & $\left.\frac{\mathrm{KBw}^{1 / 2}}{\mathrm{P}}\right|_{\text {average }}$ & $\frac{\mathrm{EBV}_{\mathrm{L}}}{\mathrm{P}}$ & $\frac{\mathrm{EBV}_{\mathrm{T}}}{\mathrm{P}}$ \\
\hline 0.0 & 26.33 & 28.03 & 79.2 & 77.5 \\
0.17 & 26.92 & 28.49 & 77.9 & 76.1 \\
0.3 & 27.73 & 29.20 & 75.5 & 73.6 \\
0.49 & 27.99 & 29.12 & 64.4 & 63.1 \\
\hline
\end{tabular}

The normalized stress-intensity factors at the midplane are higher for higher Polsson's ratios, and they change as much as six percent as the Polsson's ratio charges from 0 to 0.49 . The average normalized stressintensity factors show similar trends but with a smaller change, about 4 percent. These results indicate that a specimen with $\nu=0.17$ (fused quartz) would have a stress-intensity factor about 2.5 percent lower than a specimen with $v=0.3$ 
In contrast to the stress-intensity factors, the load-1ine displacements are lower for higher Polsson's ratios. Also, as Polsson's ratio changes from 0 to 0.3 , the change in the load-1ine displacements is about 5 percent. But as Polsson's ratio changes from 0.3 to 0.49 , the load-1ine displacements change by as much as 15 percent.

\section{CONCLUSIONS}

Three-dimensional elastic finite-element analyses were used to obtain stress-intensity factors and crack-opening displacements for chevron-notched fracture specimens. Two types of specimens, a chevron-notched bar and rod, were subjected to simulated wedge loading (either uniform load or uniform displacement). The bar specimens had a height-to-width ratio of 0.435 or 0.5 . In the analyses, the crack fronts and chevron-notch sides were assumed to be straight and the slot height for the chevron cutter was taken as zero. The crack-1ength-to-specimen-width ratio (a/w) ranged from 0.4 to 0.7 . The widthto-thickness ratios $(w / B)$ were 1.45 or 2 . Stress-intensity factor variations along the crack front for these configurations were obtained by a nodal-force method. Also, "average" stress-intensity factors were obtained by a compliance method. Based on these analyses, the following conclusions were made:

1. The type of loading, either uniform load or uniform displacement, has no significant effect on stress-intensity factors and displacements.

2. The calculated load-line displacements at the top of the specimens are about 5 percent lower than reported experimental values. 
3. The stress-intensity factor is lowest at the midplane of the specimen and highest at the intersection of the crack with the chevron notch. For most of the crack front, however, the stress intensity factor is nearly constant. The rise occurs in the close vicinity of the chevron notch.

4. The "average" stress-intensity factor obtained from the threedimensional finite-element compliance method (plane-gtress) is about 2.5 percent lower than reported experimental values for both the square bar and rod specimens.

5. The $a / w$ ratio at which the minimum stress-intensity factor occurred was between 0.5 and 0.55 for all chevron-notched configurations analyzed. 


\section{REFERENCES}

[1] Barker, L. M.: "A Simplified Method for Measuring Plane Strain Fracture Toughness," Engineering Fracture Mechanics, Vo1. 9, 1977, pp. 361-369.

[2] Barker, L. M.: "Short Bar Specimens for $\mathrm{K}_{\mathrm{IC}}$ Measurements, American Society for Testing and Materials," ASTM STP-678, 1979, pp. 73-82.

[3] Barker, L. M.; and Guest, R. V.: "Compliance Calibration of the Short Rod Fracture Toughness Specimen," Terra Tek Report TR 78-20, 1978.

[4] Munz, D.; Bubsey, R. T.; and Srawley, J. E.: "Compliance and Stress Intensity Coefficlents for Short Bar Specimens with Chevron Notches Useful for Fracture Toughness Testing of Ceramics," International Journal of Fracture, Vo1. 16, No. 4, 1980, pp. 359-374.

[5] Bubsey, R. T.; Munz, D.; Plerce, W. S.; and Shannon, J. L., Jr.: "Compliance Callbration of the Short Rod Chevron-Notch Specimen for Fracture Toughness Testing of Brittle Materia1s," International Journal of Fracture, Vo1. 18, No. 1, 1982, pp. 125-132.

[6] Shannon, J. L., Jr.; Bubsey, R. T.; Plerce, W. S.; and Munz, D.:

"Extended Range Stress Intensity Factor Expressions for Chevron-Notched Short Bar and Short Rod Fracture Toughness Specimens," International Journal of Fracture, Vo1. 19, No. 3, 1982, pp. R55-R58.

[7] Barker, L. M.: "Compllance Calibration of a Family of Short Rod and Short Bar Fracture Toughness Specimens," Engineering Fracture Mechanics, Vol. 17, No. 4, 1983, pp. 289-312.

[8] Bluhm, J. I.: "Slice Synthesis of a Three-Dimensional 'Work of Fracture" Specimen," Engineering Fracture Mechanics, Vol. 7, 1975, pp. 593-604.

[9] Beech, J. F.; and Ingraffea, A. R.: "Three-Dimensional Finfte Element Calibration of the Short Rod Specimen," International Journal of Fracture, Vo1. 18, No. 3, 1982, pp. 217-229. 
[10] Raju, I. S.; and Newman, J. C., Jr.: "Three-Dimensional Finite-Element Analysis of Finite-Thickness Fracture Specimens," NASA TN D-8414, National Aeronautics and Space Administration, Washington, DC, 1977.

[11] Raju, I. S.; and Newman, J. C., Jr.: "Stress-Intensity Factors for a Wide Range of Semi-Elliptical Surface Cracks In Finite-Thickness Plates," Engineerlng Fracture Mechanics, Vol. 11, No. 4, 1979, pp. $817-829$.

[12] Newman, J. C., Jr॰: "Stress Analysis of the Compact Specimen Including the Effects of PIn Loading," American Society for Testing and Materials, ASTM STP-560, 1974, pp. 105-121.

[13] Hartranft, R. J.; and Sih, G. C.: "An Approximate Three-Dimensional Theory of Plates With Application to Crack Problems," International Journal of Engineering Sclence, Vo1. 8, No. 8, 1970, pp. 711-729.

[14] Barker, L. M.: "Short Rod $\mathrm{K}_{\mathrm{Ic}}$ Measurements of $\mathrm{Al}_{2} \mathrm{O}_{3}$," Fracture Mechanics of Ceramics, Vo1. 3, R. C. Bradt, D. P. H. Hasselman, and F. F. Lange, eds., Plenum Publishing, 1978, p. 483.

[15] Timoshenko, S.; and Goodier, J. N.: Theory of Elasticity. Second ed. McGraw-HIII Book Co., Inc., 1951. 
Table 1.- Boundary-correction factor, F, distributions for chevron-notched bar (square) specimens.

$$
\text { (a) } \mathrm{KBw}^{1 / 2} / \mathrm{P} \text { for } \mathrm{w} / \mathrm{B}=1.45
$$

\begin{tabular}{llllll}
\hline$\frac{2 z}{b}$ & 0.4 & 0.5 & 0.55 & 0.6 & 0.7 \\
\hline 0.0 & 27.95 & 23.83 & 23.50 & 24.45 & 30.37 \\
0.5 & 28.82 & 24.19 & 24.08 & 24.96 & 30.76 \\
0.75 & 30.59 & 25.69 & 25.46 & 26.23 & 31.84 \\
0.875 & 32.45 & 27.49 & 27.19 & 27.90 & 33.46 \\
0.9375 & 33.56 & 29.49 & 29.33 & 30.17 & 36.09 \\
1.0 & 36.66 & 32.30 & 32.30 & 33.38 & 40.17 \\
\hline
\end{tabular}

(b) $\mathrm{KB} w^{1 / 2} / \mathrm{P}$ for $\mathrm{w} / \mathrm{B}=2$

\begin{tabular}{llllll}
\hline$\frac{2 z}{b}$ & 0.4 & 0.5 & 0.55 & 0.6 & 0.7 \\
\hline 0.0 & 28.28 & 27.98 & 28.43 & 29.33 & 33.86 \\
0.5 & 29.14 & 28.60 & 28.93 & 29.71 & 33.96 \\
0.75 & 31.11 & 30.16 & 30.27 & 30.80 & 34.54 \\
0.875 & 33.48 & 32.21 & 32.13 & 32.46 & 35.78 \\
0.9375 & 36.09 & 35.00 & 34.89 & 35.17 & 38.43 \\
1.0 & 41.42 & 40.26 & 40.17 & 40.48 & 44.12 \\
\hline
\end{tabular}


Table 2.- Boundary-correction factor, F, distributions for chevron-notched rod specimens.

(a) $\mathrm{KBw}^{1 / 2} / \mathrm{P}$ for $\mathrm{w} / \mathrm{B}=1.45$

\begin{tabular}{llllll}
\hline$\frac{2 z}{b}$ & 0.5 & 0.55 & 0.6 & 0.7 \\
\hline 0.0 & 33.52 & 27.97 & 27.73 & 28.84 & 34.19 \\
0.5 & 34.53 & 28.64 & 28.24 & 28.87 & 34.13 \\
0.75 & 36.60 & 30.22 & 29.55 & 29.89 & 34.47 \\
0.875 & 38.77 & 32.17 & 31.30 & 31.44 & 35.54 \\
0.9375 & 40.07 & 34.37 & 33.57 & 33.70 & 37.80 \\
1.0 & 43.70 & 37.51 & 36.76 & 37.01 & 41.56 \\
\hline
\end{tabular}

(b) $\mathrm{KBw} w^{1 / 2} / \mathrm{P}$ for $\mathrm{w} / \mathrm{B}=2$

\begin{tabular}{llllll}
\hline$\frac{2 z}{b}$ & 0.4 & 0.5 & 0.55 & 0.6 & 0.7 \\
\hline 0.0 & 34.68 & 34.62 & 35.30 & 36.44 & 41.28 \\
0.5 & 35.59 & 35.12 & 35.55 & 36.42 & 40.57 \\
0.75 & 37.74 & 36.55 & 36.55 & 36.93 & 39.85 \\
0.875 & 40.40 & 38.63 & 38.26 & 38.22 & 40.11 \\
0.9375 & 43.40 & 41.65 & 41.13 & 40.86 & 42.11 \\
1.0 & 49.61 & 47.58 & 46.91 & 46.46 & 47.40 \\
\hline
\end{tabular}


Table 3.- Normalized displacements as a function of $a / w$ for chevron-notched square bar and rod specimens

(a) $\mathrm{EBV}_{L} / \mathrm{P}$ at midplane $(\mathrm{x}=\mathrm{z}=0 ; y=0.35 \mathrm{H})$

\begin{tabular}{llrrrrr}
\hline Type & w/B & \multicolumn{5}{c}{ a/w } \\
& & 0.4 & 0.5 & 0.55 & 0.6 & 0.7 \\
\hline Bar(a) & 1.45 & 35.5 & 47.6 & 56.2 & 67.3 & 103.0 \\
$\operatorname{Bar}(a)$ & 2 & 55.5 & 82.6 & 99.8 & 119.0 & 174.5 \\
$\operatorname{Rod}$ & 1.45 & 46.9 & 63.7 & 75.5 & 90.2 & 135.1 \\
$\operatorname{Rod}$ & 2 & 76.3 & 116.1 & 141.4 & 171.3 & 249.8 \\
\hline
\end{tabular}

(a) Square bar $(\mathrm{H} / \mathrm{B}=0.5)$

(b) $\mathrm{EBV}_{\mathrm{T}} / \mathrm{P}$ at midplane $(\mathrm{x}=\mathrm{z}=0 ; \quad \mathrm{y}=\mathrm{H})$

\begin{tabular}{lllllll}
\hline Type & w/B & & \multicolumn{5}{c}{$a / w$} \\
& & 0.4 & 0.5 & 0.55 & 0.6 & 0.7 \\
\hline $\operatorname{Bar}^{(a)}$ & 1.45 & 33.9 & 46.0 & 54.6 & 65.5 & 101.3 \\
$\operatorname{Bar}^{(a)}$ & 2 & 54.0 & 81.1 & 98.3 & 118.5 & 173.0 \\
$\operatorname{Rod}$ & 1.45 & 45.1 & 61.9 & 73.6 & 88.3 & 133.2 \\
$\operatorname{Rod}$ & 2 & 74.7 & 114.4 & 139.7 & 169.6 & 248.1 \\
\hline
\end{tabular}

(a) Square bar $(\mathrm{H} / \mathrm{B}=0.5)$ 


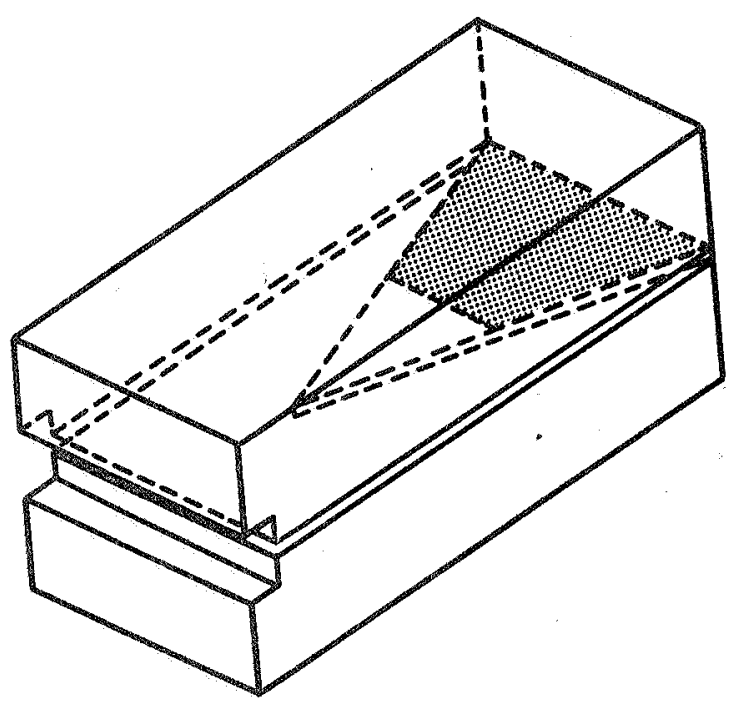

(a) Bar:

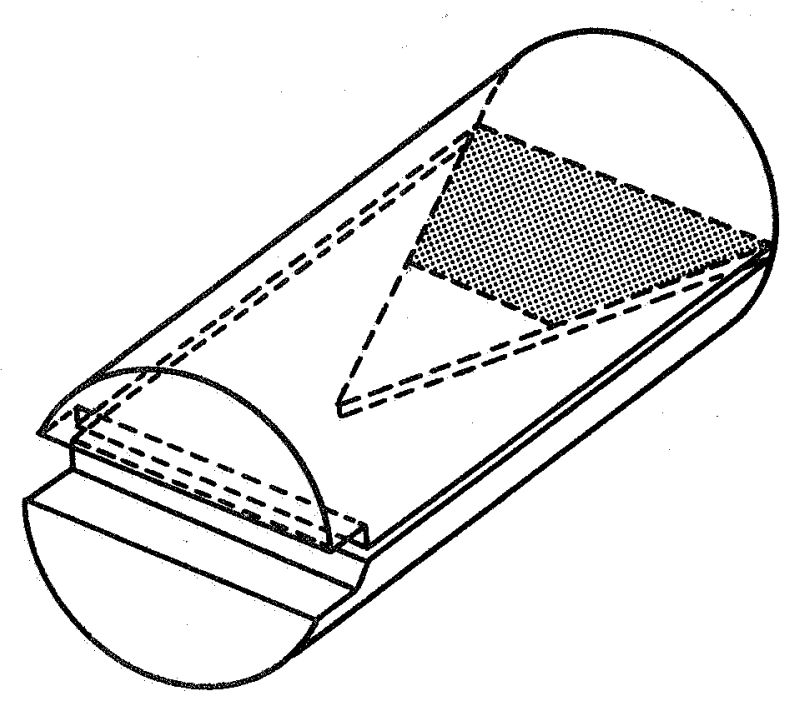

(b) Rod.

Figure 1.- Chevron-notched bar and rod specimens. 


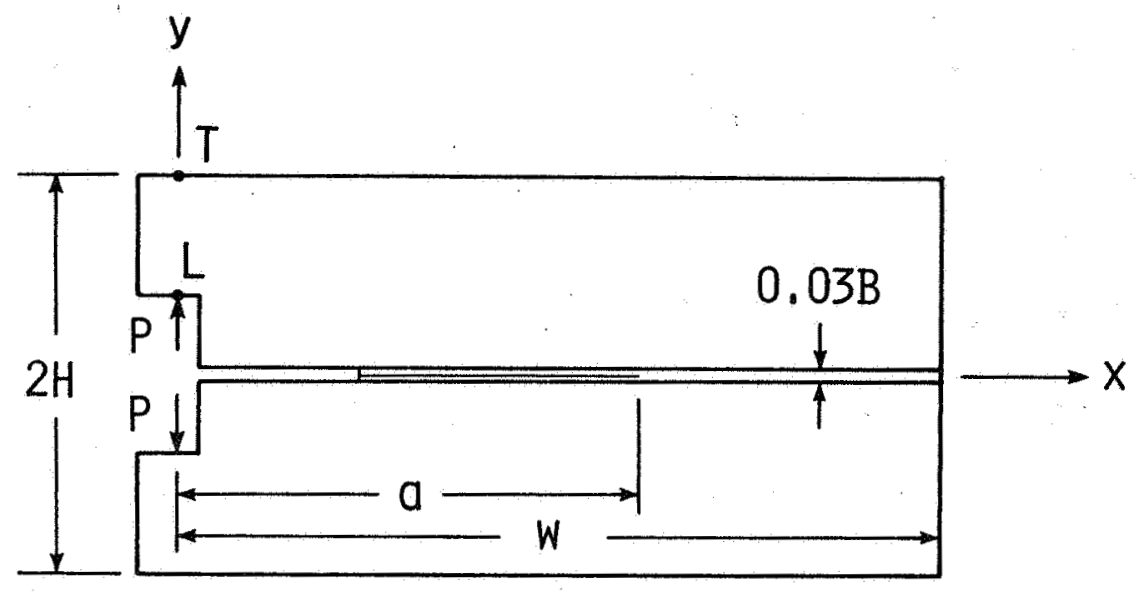

(a) $z=0$ plane,

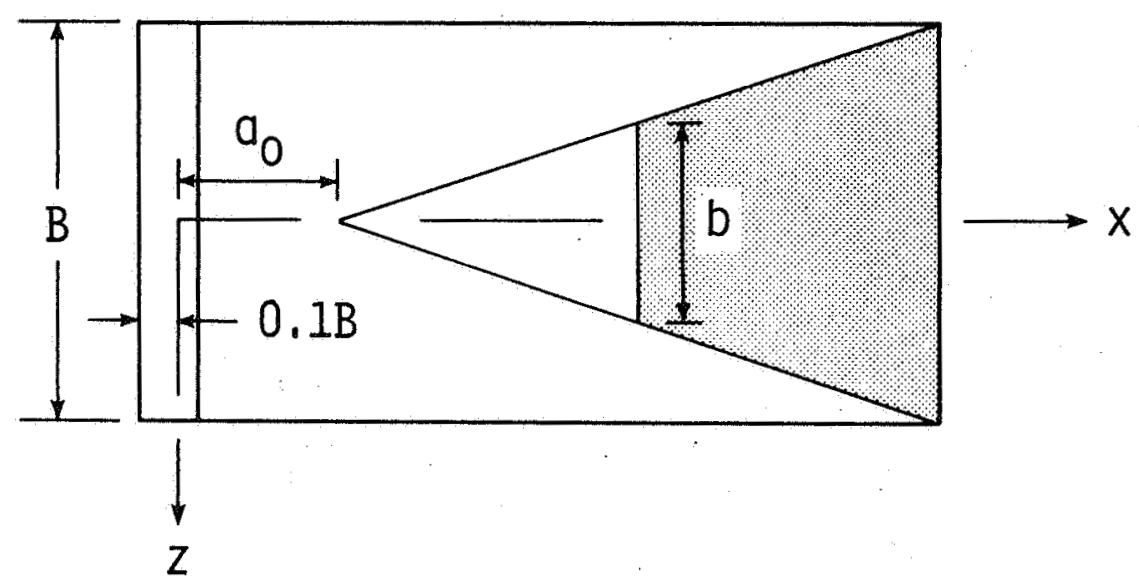

(b) $y=0$ plane.

Figure 2.- Coordinate system used to define dimensions of chevron-notched specimens. 

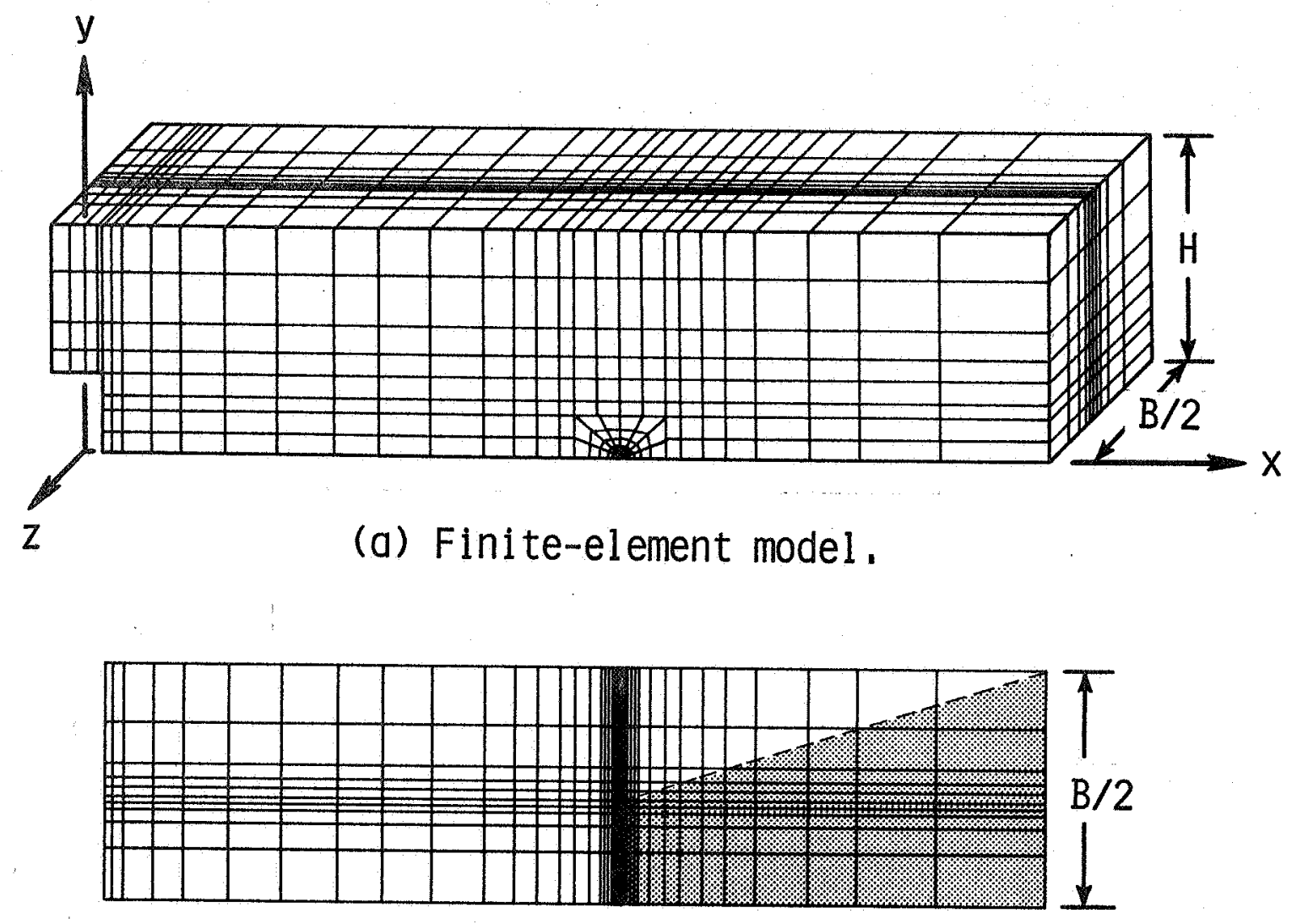

(b) Element pattern on $y=0$ plane.

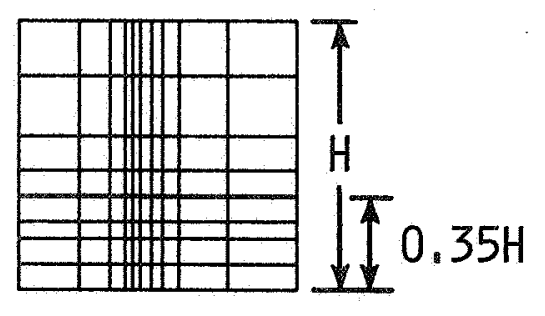

(c) End view of bar.

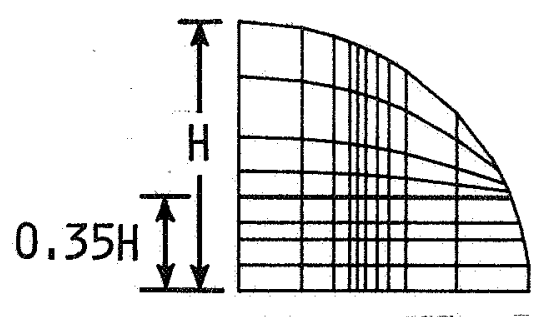

(d) End view of rod.

Figure 3.- Finite-element idealization of chevron-notched bar and rod specimens. 

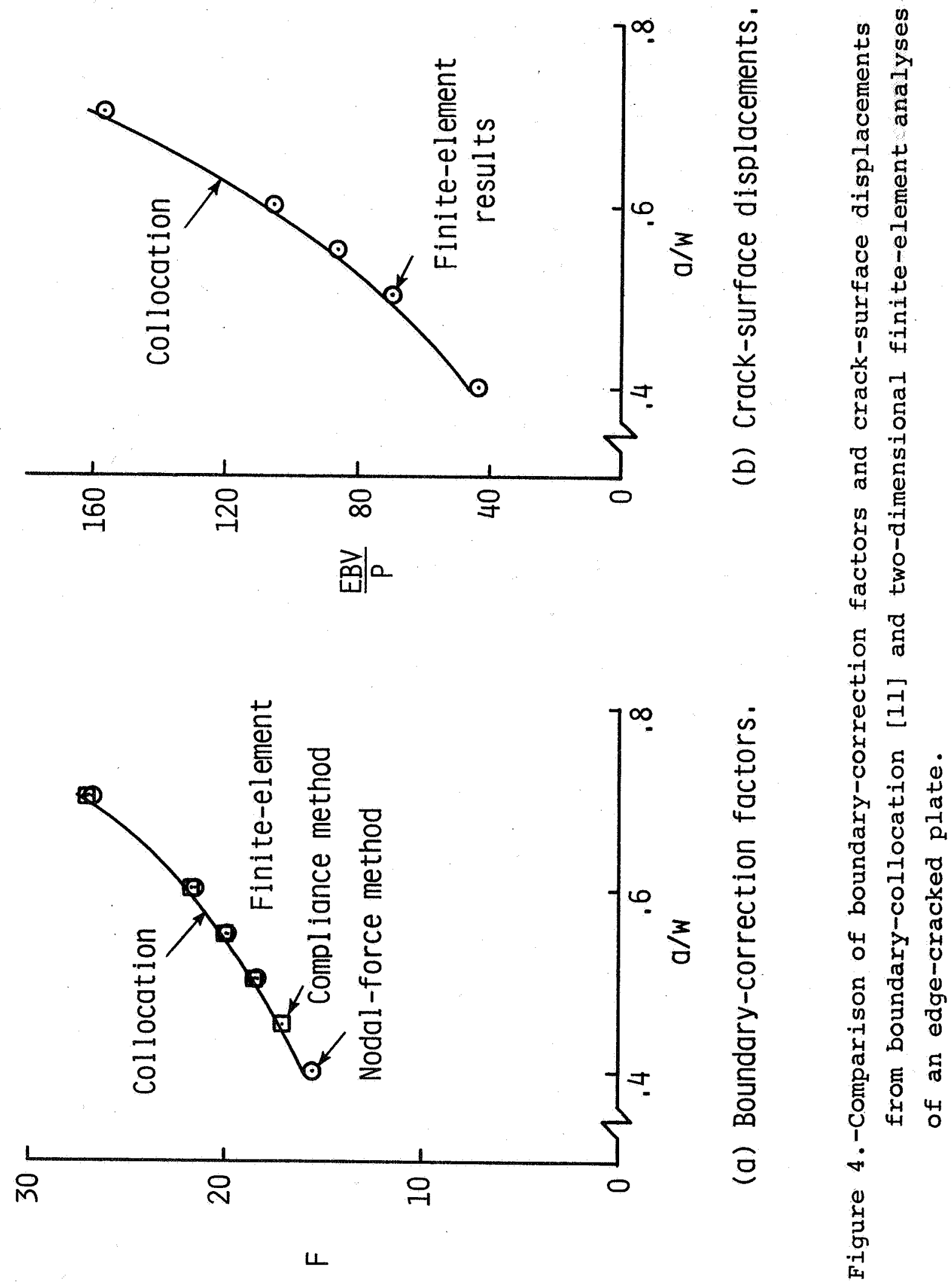


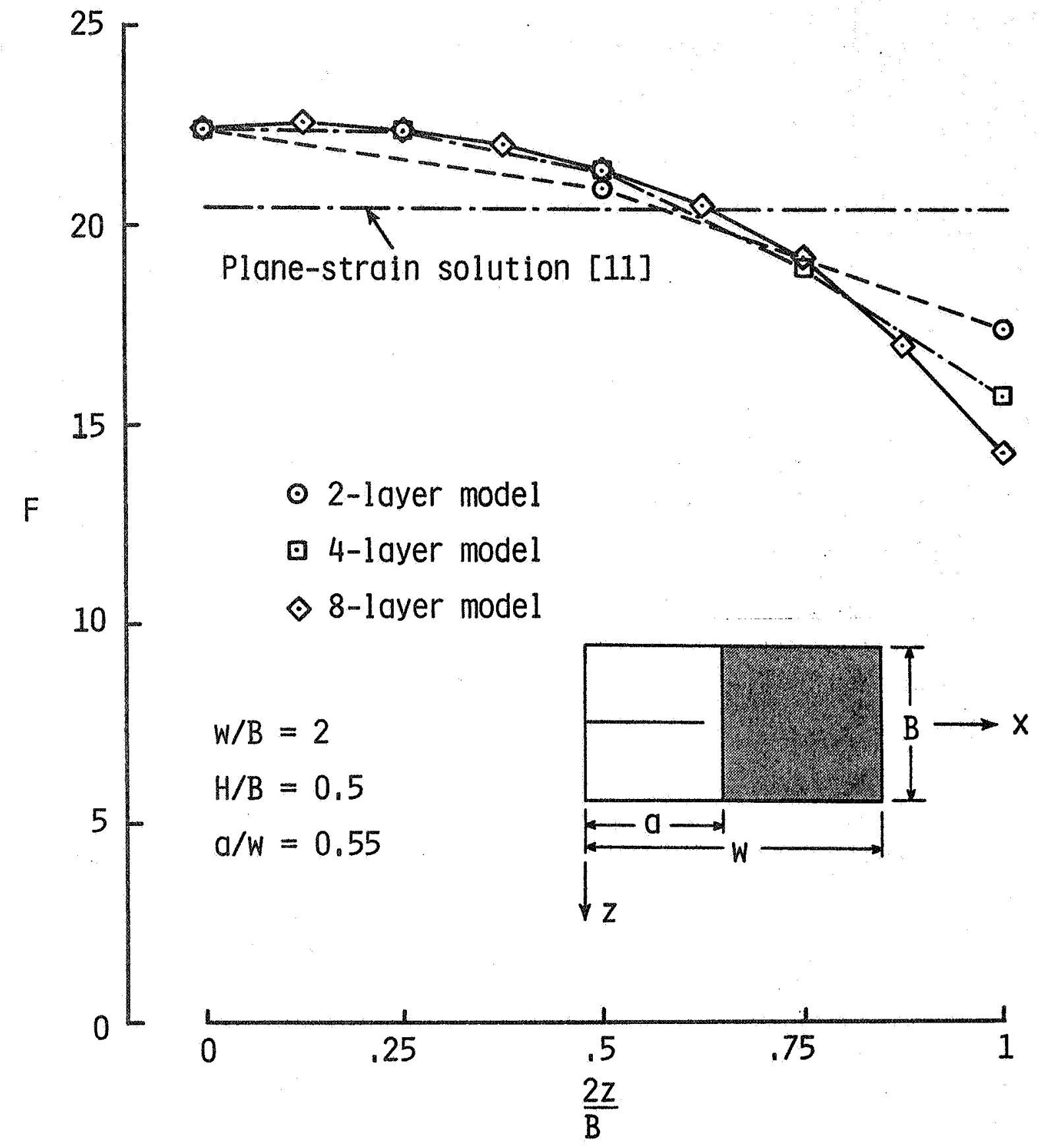

Figure 5.- Distribution of boundary-correction factors along crack front for through crack in an edge-cracked plate using various three-dimensional finite-element models. 


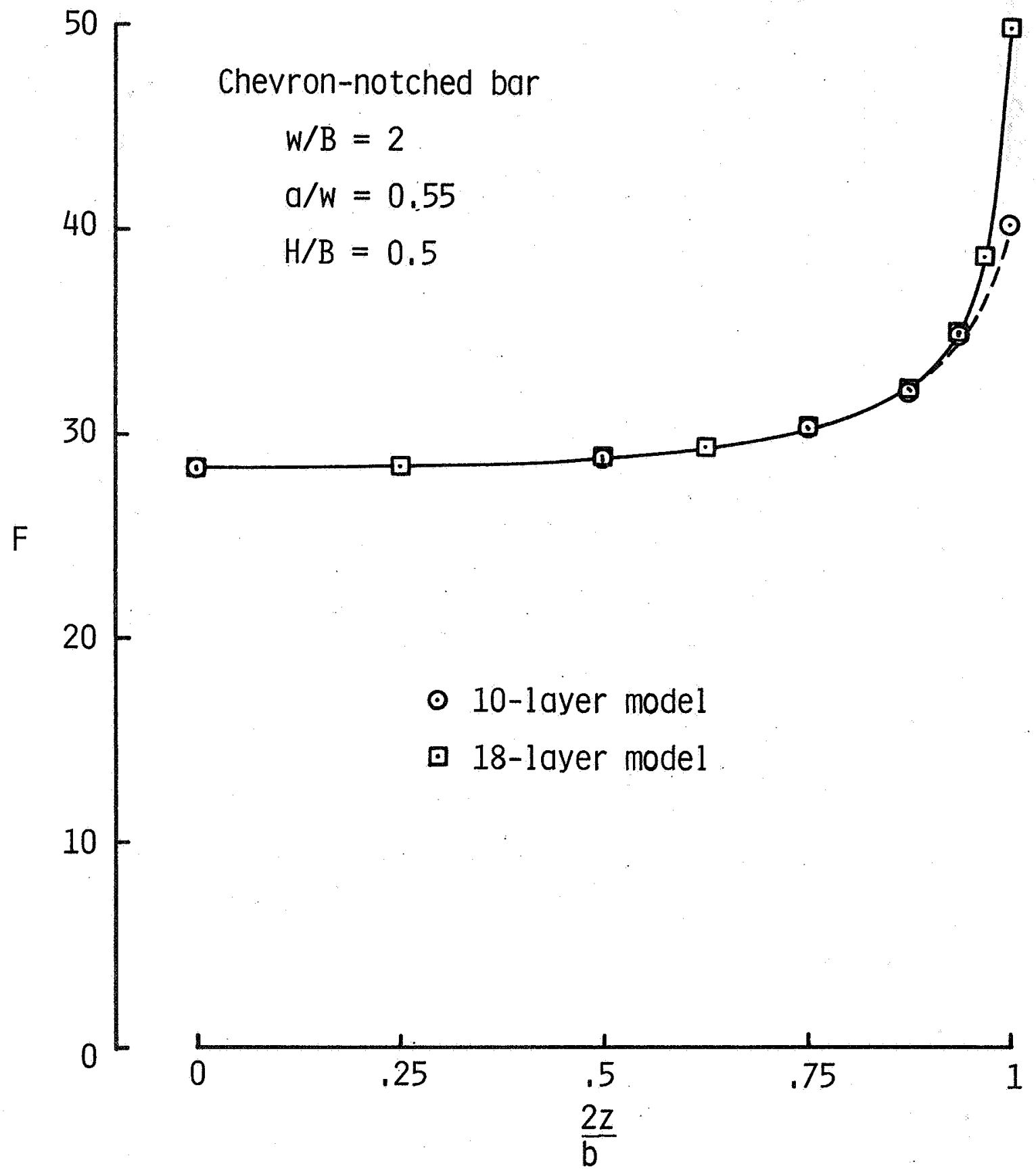

Figure 6.- Distribution of boundary-correction factors along crack front in chevron-notched bar for two finiteelement models. 


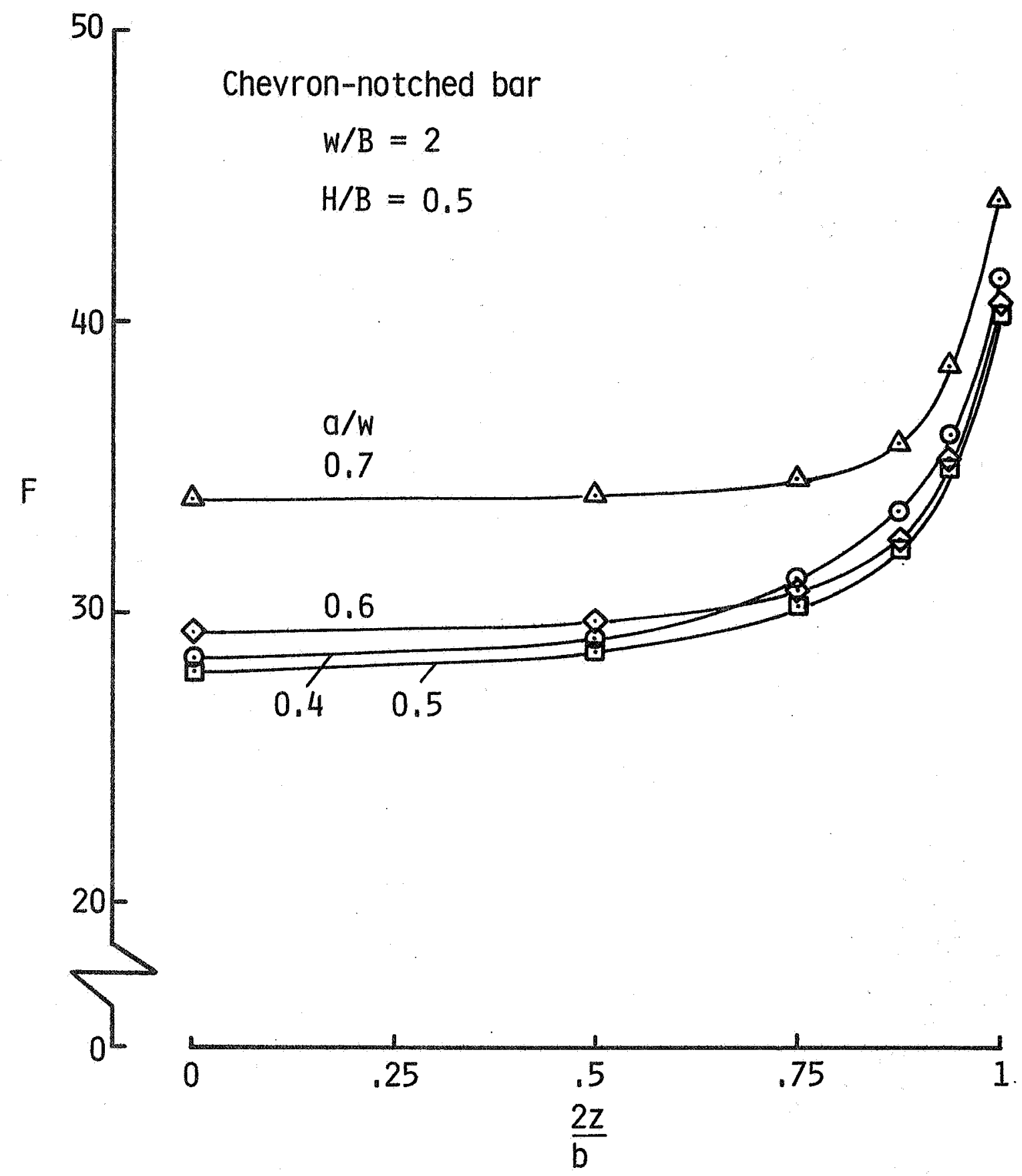

Figure 7.- Distribution of boundary-correction factors along crack front in chevron-notched bars with various crack-length-to-width ratios. 


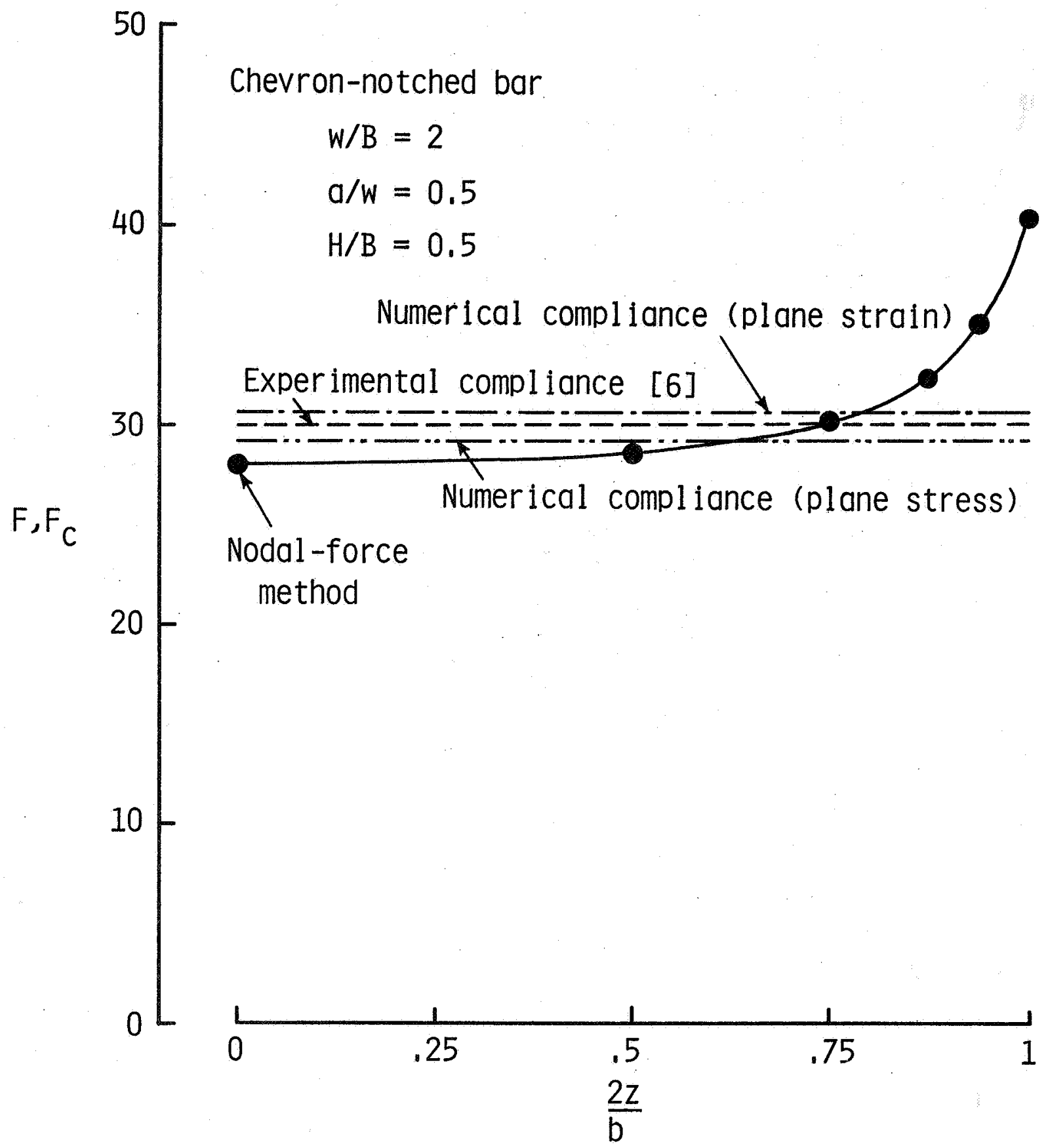

Figure 8.- Comparison of boundary-correction factors from nodalforce and compliance methods for chevron-notched bar. 


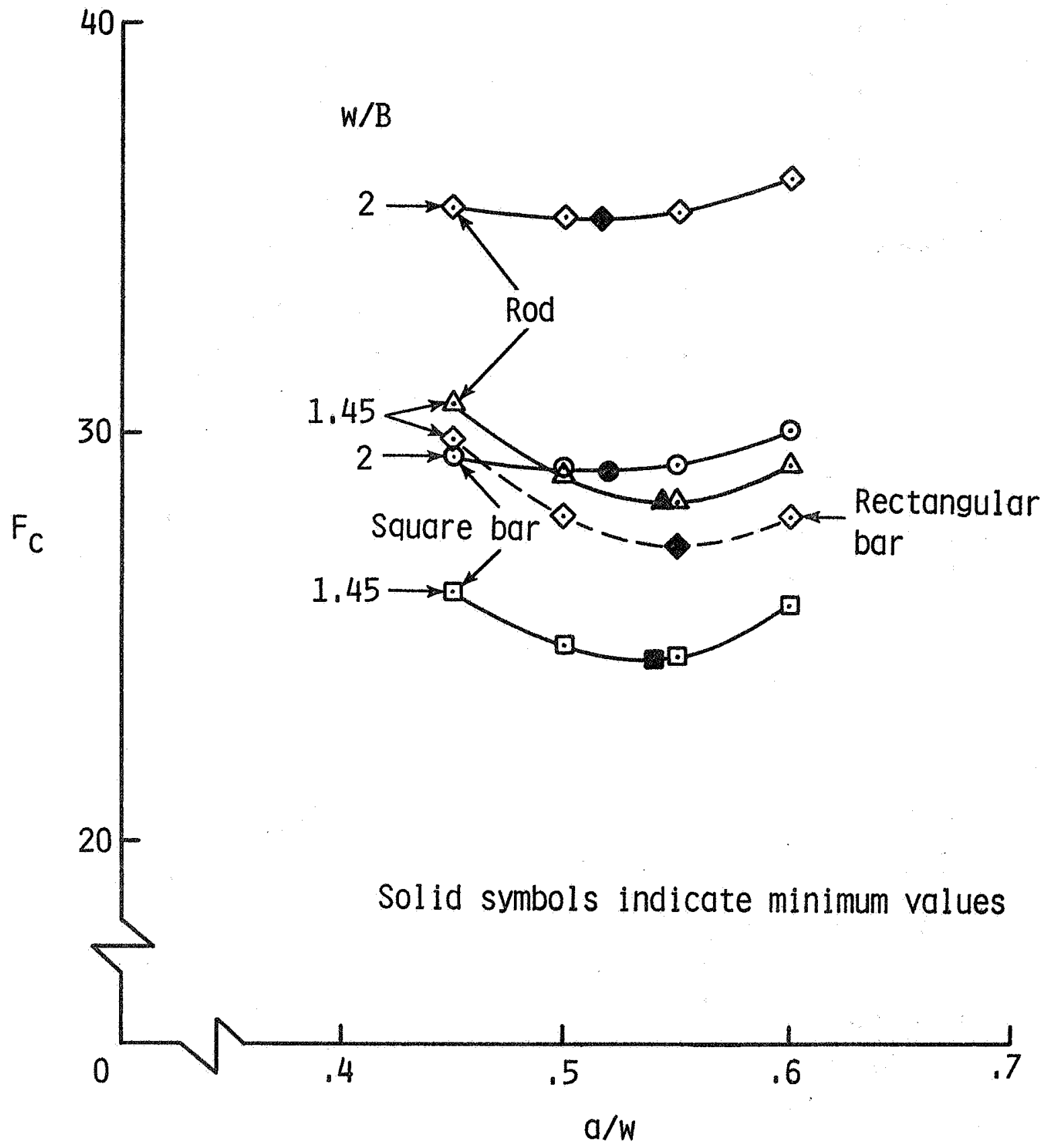

Figure 9.- Comparison of boundary-correction factors from numerical compliance method for chevron-notched bar and rod specimens. 


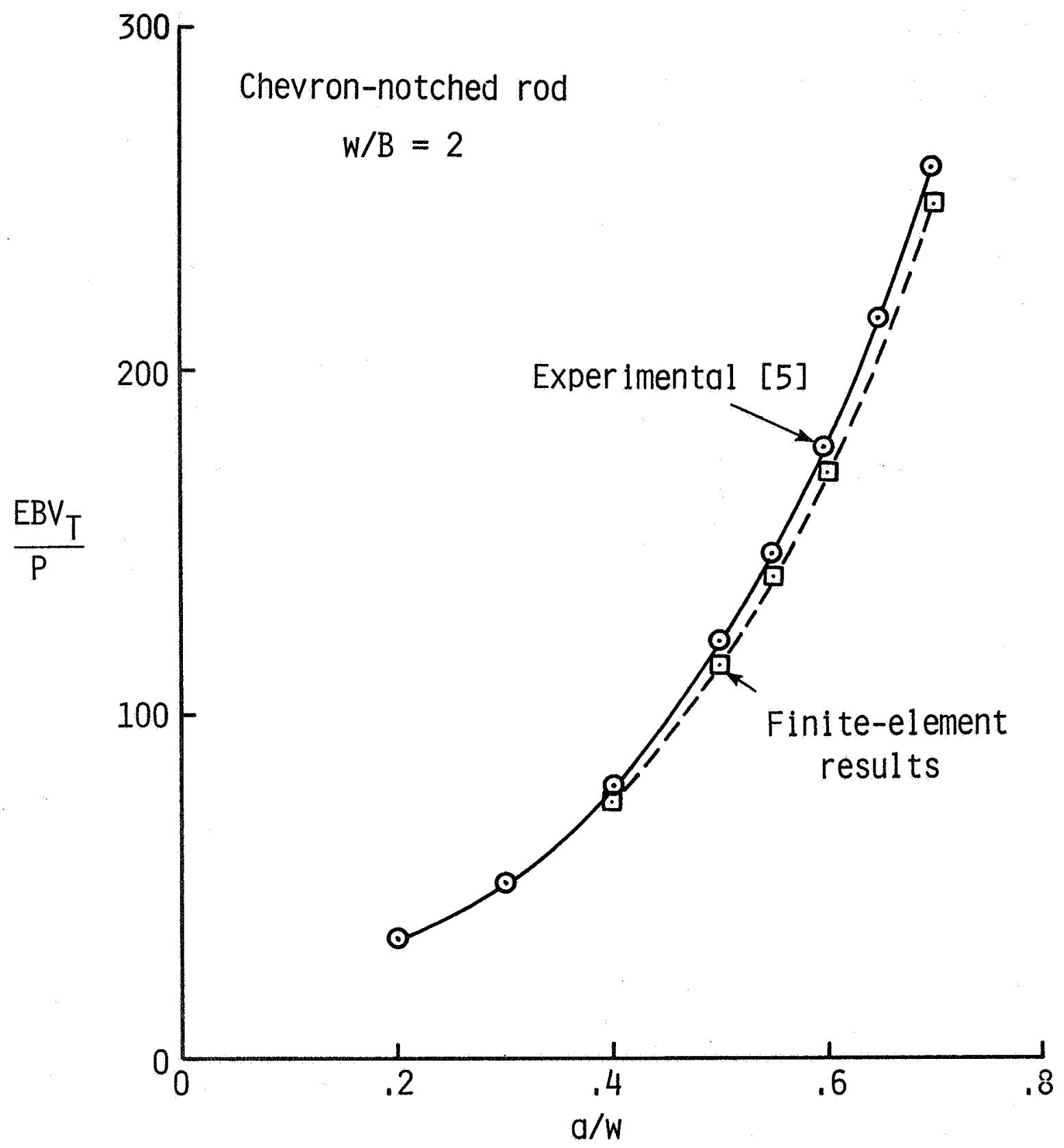

Figure 10.- Comparison of experimental and calculated load-line displacements for chevron-notched rod. 


\begin{tabular}{|c|c|c|}
\hline $\begin{array}{l}\text { 1. Report No. } \\
\text { NASA TM-85798 }\end{array}$ & 2. Government Accession No. & 3. Recipient's Catalog No. \\
\hline \multirow{2}{*}{\multicolumn{2}{|c|}{$\begin{array}{l}\text { 4. Title and Subtitle } \\
\text { THREE-DIMENSIONAL FINITE-ELEMENT ANALYSIS OF CHEVRON- } \\
\text { NOTCHED FRACTURE SPECIMENS }\end{array}$}} & $\begin{array}{l}\text { 5. Report Date } \\
\text { July } 1984\end{array}$ \\
\hline & & $\begin{array}{l}\text { 6. Performing Organization Code } \\
505-33-23-02\end{array}$ \\
\hline \multicolumn{2}{|c|}{$\begin{array}{l}\text { 7. Author(s) } \\
\text { I. S. Raju and J. C. Newman, Jr. }\end{array}$} & 8. Performing Organization Report No. \\
\hline \multirow{3}{*}{\multicolumn{2}{|c|}{$\begin{array}{l}\text { 9. Performing Organization Name and Address } \\
\text { NASA Langley Research Center } \\
\text { Hampton, Virginia } 23665\end{array}$}} & 10. Work Unit No. \\
\hline & & 11. Contract or Grant No. \\
\hline & & \multirow{2}{*}{$\begin{array}{l}\text { 13. Type of Report and Period Covered } \\
\text { Technical Memorandum }\end{array}$} \\
\hline \multirow{2}{*}{\multicolumn{2}{|c|}{$\begin{array}{l}\text { 12. Sponsoring Agency Name and Address } \\
\text { National Aeronautics and Space Administration } \\
\text { Washington, DC } 20546\end{array}$}} & \\
\hline & & 14. Sponsoring Agency Code \\
\hline
\end{tabular}

15. Supplementary Notes

16. Abstract

In this paper, stress-intensity factors and load-line displacements have been calculated for chevon-notched bar and rod fracture specimens using a three-dimensional finite-element analysis. Both specimens were subjected to simulated wedge loading (either uniform applied displacement or uniform applied load). The chevron-notch sides and crack front were assumed to be straight. Crack-length-to-specimen width ratios $(\mathrm{a} / \mathrm{w})$ ranged from 0.4 to 0.7 . The width-to-thickness ratio (w/B) was 1.45 or 2 . The bar specimens had a height-to-width ratio of 0.435 or 0.5 . Finite-element models were composed of singularity elements around the crack front and 8-noded isoparametric elements elsewhere. The models had about 11,000 degrees of freedom. Stress-intensity factors were calculated by using a nodal-force method for distribution along the crack front and by using a compliance method for average values. The stress-intensity factors and load-line displacements are presented and compared with experimental solutions from the literature. The stress-intensity factors and load-line displacements were about 2.5 and 5 percent lower than the reported experimental values, respectively.

17. Key Words (Suggested by Author(s))

Chevron-notch, stress-intensity factor, cracks, finite-element analys is
18. Distribution Statement

Unclassified - Unlimited

Subject Category 39
19. Security Classif (of this report) Unclassified

20. Security Classif. (of this page)
Unclassified

20. Security Classif. (of this page) Unclassified
21. No. of Pages 33
22. Price $\mathrm{A} 03$ 